\title{
Revisiting Deep Disagreement
}

\author{
Dale Turner \\ California State Polytechnic University, \\ Pomona
}

\section{LARRY WRIGHT University of California, Riverside}

\begin{abstract}
Argument-giving reasons for a view-is our model of rational dispute resolution. Fogelin (1985) suggests that certain "deep" disagreements cannot be resolved in this way because features of their context "undercut the conditions essential to arguing" (p. 5). In this paper we add some detail to Fogelin's treatment of intractable disagreements. In doing so we distinguish between his relatively modest claim that some disputes cannot be resolved through argument and his more radical claim that such disputes are beyond rational resolution. This distinction, along with some of the detail we add to Fogelin's treatment, sheds some useful light on the project of informal logic.
\end{abstract}

Résumé: L'argumentation-la proposition de raisons pour soutenir un jugement-est notre modèle de résolution de désaccord. Fogelin (1985) suggère que certains désaccords "profonds» ne peuvent pas se résoudre par l'argu-mentation parce que des aspects d'un contexte de contestation "étouffent les conditions nécessaires de l'argumentation» (p. 5). Dans cet article nous ajoutons des détails à l'approche de Fogelin sur les désaccords difficiles à résoudre. Nous distinguons son opinion relativement modeste que l'argumentation ne peut pas résoudre certains désaccords et son opinion plus radicale que de tels désaccords sont au-delà de résolutions rationnelles. Cette distinction ainsi que d'autres informations sur l'approche de Fogelin éclairent d'avantage le projet de la logique non formelle.

Keywords: Fogelin, deep disagreement, articulation, understanding

\section{Introduction: Disagreement and the Function of Argument}

Argument-explicitly setting out reasons for something--can have a number of functions. It can be used to articulate a position to oneself or to an audience; to show to oneself or others that a position is at least reasonable; as a tool of intellectual exploration or inquiry; and to help locate areas of disagreement with or without the intention of addressing those areas. But clearly, one of the most obvious and important functions of argument is the actual resolution of disagreement. We often offer reasons for a view with the expectation that this will end disagreement in a way that may be certified as rational. In fact, part of what motivates both philosophical inquiry in general and the informal logic movement as a specialized branch of it, is the sense that real progress can be made in the adjudication of intellectual disputes-whether they be about age-old philosophical controversies 
such as the existence of freewill, the rationality of the fear of death, the desirability of embodied immortality, the nature and status of our epistemic claims, the nature of moral judgment, or contemporary social controversies such as abortion, euthanasia, sexual morality, capital punishment, the war in Iraq, taxation, or the privatization of education and social security-by the careful construction and analysis of arguments.

It is easy to see why we have such high expectations for argument. The use of argument to adjudicate controversy can be inclusive and democratic. Moreover, and perhaps more importantly, in countless mundane cases of disagreement we employ argument with great success. For example, arguing that the heavy snowfall in the mountains makes it reasonable to take the coastal route typically just ends whatever disagreement two interlocutors might have had about how to get to their destination. We expect it, then, to pay dividends in the more controversial aspects of our social and intellectual lives as well.

This transfer of expectations has not gone unchallenged, however. Twenty years ago Robert Fogelin (1985) suggested that in contexts of what he calls "deep disagreement," argument fails to provide a means of rational dispute resolution: "deep disagreements cannot be resolved through the use of argument, for they undercut the conditions essential to arguing" (p. 5). This is no mere philosophical abstraction but rather something that applies to at least some of the items listed above that are of central interest to the Informal Logic movement. Furthermore, Fogelin thinks this may place the issues themselves beyond reason: "there are," he concludes, "disagreements, sometimes on important issues, which by their very nature, are not subject to rational resolution" (p. 7). Although this view has been both attacked and defended in this journal, (Lugg, 1986; Davson-Galle, 1992) it has been largely ignored in the teaching of controversy. This may in part be due to the difficulty of the issue itself; but part of the problem may be that both Fogelin and his defenders obscure things by running together two distinguishable propositions.

In this paper we would like to look a bit more closely at the difficult questions underlying the tractability of disagreement. In doing this we will distinguish Fogelin's more modest claim that there are contexts of deep disagreement in which argument fails to live up to its dialectical promise ${ }^{1}$ from his more radical claim that deep disagreements are not subject to rational resolution at all. Our hope is to cast some useful light on the project of Informal Logic.

\section{Getting clear on deep disagreement}

To understand the nature and significance of deep disagreement Fogelin directs our attention to contexts of "normal or near normal argumentative exchanges" ( $p$. 4) such as the travel route example mentioned above. In such contexts interlocutors share a background of commitments and understanding, including much about what counts as a resolution of disagreement. Fogelin's Wittgensteinian view is that 
it is these conditions that give argument whatever interest and value it has for us: "the possibility of genuine argumentative exchange depends ... on the fact that together we accept many things" (p. 4). And if there are non-normal argumentative exchanges in which interlocutors fail to share a common core of framework propositions, then, "argument, to that extent, becomes impossible" (p. 4). Fogelin clearly thinks that there are circumstances or contexts that do fail to meet these minimal conditions for genuine or productive argument, dubbing exchanges arising in such cases "deep disagreements."

This is not the weak claim that in such contexts arguments cannot be settled.

It is the stronger claim that the conditions for argument do not exist. The language of argument may persist, but it becomes pointless since it makes an appeal to something that does not exist: a shared background of beliefs and preferences. (pp. 4-5)

Argument then ceases to be a tool for the rational resolution of disagreement; one of the primary functions of argument is undermined in such contexts.

To see how such contexts might undermine the conditions that make argument possible, it would be good to be clear about what those conditions are. As a step in that direction, consider the following conversational sketches in the ordinary human circumstances they each suggest.

1. A colleague asks about an oil stain under my car. I tell her that my car must have an oil leak since the stain is new and the car hasn't been moved for a while. She thinks I must be right.

2. Several students drop by a professor's office during scheduled office hours to ask about a quiz. The professor's door is open but she is not in the office. One student suggests that she is gone for the day, but another points out that she just saw the instructor in class and that there is a steaming cup of coffee on her desk. The students jointly conclude that the instructor is around somewhere and will be back shortly.

3. Laura asserts that her husband is having an affair. Her friend says that she cannot imagine that John could do that sort of thing. Laura replies by pointing out that he has consistently been home late for the past two weeks, often smells of a perfume that she doesn't wear, and is trying to hide the fact that he is calling the number of a high school sweetheart that he recently ran into at his ten year reunion. Her friend finds it impossible to resist Laura's conclusion.

4. While out running errands together, my wife recommends that we go to the dry cleaner before the grocery store. When I ask why she says simply: we need ice cream. I head for the dry cleaners. ${ }^{2}$

5. Sara suggests to her husband that they go visit her mother. When asked for a reason she responds by pointing out that a preemptive visit will preclude her mother from visiting them. Her husband concurs.

In these cases of normal argumentative exchange, offering reasons successfully produces intersubjective agreement. Of course, things need not go so smoothly in any of these cases: complications and further disagreements can easily arise. But 
because these examples were all chosen to illustrate Fogelin's normal circumstance in which interlocutors share nearly everything relevant to the exchange, they would also have a pretty clear sense of how to proceed in settling the matter if the first gambit was not immediately successful.

To begin to see how and why departing very far from the congenial conditions illustrated here might undermine the very possibility of argument, it would be worth saying a bit more than Fogelin does about just what it is in these conditions that underwrites that possibility. The first thing to note is that what the interlocutors share in such cases allows them to accomplish what they do quite economically. In the examples given, the entire argument may be captured in a single complex sentence in which the subordinating conjunction "because" connects the view with an item or two or three of support. The oil must have come from my car because the stain is new and the car's been there for some time. Or: we should stop at the cleaners before the grocery store because ice cream is on the shopping list. These arguments are thus easily cast into classic, schematic argument form,

$$
\frac{\mathrm{S} \text { (support) }}{\mathrm{C} \text { (conclusion) }}
$$

For instance:

S: We have ice cream on the shopping list.

$\mathrm{C}$ : We should stop at the cleaners before the grocery store.

One way to put Fogelin's point is that the classic status of this form is no accident, but is symptomatic of the central feature of normal argumentative exchanges. This is that the interlocutors share enough solid understanding of the world, the particular circumstances, and each other that the person giving the argument knows or can easily find something relatively epigrammatic that will produce agreement; and it will do so by appeal to the competent judgment of the other. Were it obvious that this describes a fundamental constraint on the use of argument, this topic would have generated no controversy. So to better see why someone might think that departing from this condition might threaten the use of argument altogether, it will be worth examining in some detail just what's entailed in meeting it.

The first thing to note is that what our common understanding allows us to omit from explicit consideration is in each case a strictly unlimited list of considerations that would be relevant to the reasoning were we not able to simply take them for granted. In the second example, for instance, we simply assume our interlocutors know roughly how fast coffee cools when sitting at room temperature and at any rate, that doesn't get hotter; that coffee is a beverage and one commonly consumed at work; that cups of warm coffee do not spontaneously materialize on desks, or even randomly; that coffee on a desk is not a common way to signal that someone has gone for the day; that classes are nearby and recognizable by ordinary students; that getting from class to office takes minutes rather than centuries; that 
people do not usually die or vanish in these circumstances; and so on. If much on this list were missing from an interlocutor's understanding, then nothing in argument form would be up to the task of addressing the disagreement. What would be needed would be on the order of an education, a richer life, or therapy, nothing that could be accomplished epigrammatically. This is the position most of us are in when the topic is exotically disciplinary. A standard paleobiological argument concludes that every organism alive today has a common ancestor of a certain quite particular makeup that lived two or three billion years ago. Its support appeals to the nature of ribonucleic acid and its function in synthesizing protein molecules, together with details of mutation rates, geophysical history, and systematic features of the fossil record. From its provenance and location we can be reasonably certain this is a good argument. But no epigrammatic augmentation of it would enable the average intelligent, educated person to evaluate it. The reasoning would be accessible only after serious immersion in a curriculum. Without that, we could not achieve agreement on its conclusion through this argument.

Furthermore, when the agreement induced by mentioning steaming coffee and the recent sighting is of the proper sort, that is, the result of these items engaging a competent judgment, this will be manifest in the intersubjective satisfactoriness of other talk and behavior. In particular, the interlocutors should go on together in fitting the support offered into various stories about the recent whereabouts of the professor: musing about possible sequences of events, for instance, or checking for coffee sources and other sightings. Were someone incapable of this, we would properly doubt that the agreement, if real at all, was due to understanding the reasons for the conclusion, as opposed to the authority of the arguer or the agreement it produced in others. The inability to do anything like this in the paleobiological case would be one manifestation of the non-specialist's incompetence in its evaluation; and it would make clear that their quite reasonable acceptance of the conclusion was based on their estimation of the argument's source and location, not its substantive detail.

In the fourth example, which is a different kind of case, we take for granted things like this too: that ice cream is frozen and that it will melt if left unrefrigerated very long on a warm day; that today is warm; that we're going by car; that the car is unrefrigerated; that the trip will take long enough to matter; and so on. But here we take for granted many explicitly normative items as well: that ice cream is better if not melted and/or refrozen; that this matters enough to affect itinerary; that configuring the trip in this way is better than making two trips, or buying another car, or skipping the ice cream, or buying something that would keep the ice cream frozen; and so on. So in cases of "practical" reasoning, explicitly concerning what we should do rather than simply what we should think, the shared perception must be expanded to include common values and preferences as well as judgments. Here again, a small difference might be treatable without leaving the context of simple reasoning: e.g., "It's too small a matter to run back for the freezer pack." But if it is not, or if the differences are large, this kind of 
case may prove even less tractable than the more or less purely "epistemic" ones of the previous example. For curricula and even greatly expanded life experience will frequently make little headway against different pictures of the good.

In any case, this way of thinking about what makes argumentative contexts "normal" allows us to provide Fogelin's deep disagreements with some fine structure that will clarify their nature and prospects. If the effortless success of "normal" appeal to reasons derives from shared understanding and uncontroversial competence, it should not be surprising that this success starts to elude us as we share less and move beyond our clear competences. And although there will be a considerable borderline of more or less indeterminate cases, we often find ourselves in circumstances in which we all recognize argument to be the wrong form in which to pursue agreement. Sometimes both sides will realize that one party needs to accumulate the understanding and develop the competence that might allow an argument to be effective. And of course pursuing this suggestion will often eliminate a disagreement without ever returning to the argument itself.

Frequently enough, however, disagreement will survive initial attempts to deal with it epigrammatically and neither side will concede that the other has any special status or advantage; and it soon becomes clear that the dispute concerns what is to count as proper understanding and genuine competence as much as it does the substantive topic. Fogelin's own examples of hot social controversy (abortion, affirmative action) seem to contain this component almost universally. But abstract philosophical controversies over the famous "isms" (realism, solipsism, idealism, empiricism, rationalism...) are equally good candidates.

This is why Fogelin's "modest" claim is not really modest at all; for if disagreement of this kind is to be expected in addressing social and philosophical disputes, then much of the motivation for the appeal to argument in such disputes is undermined. This is not to say with Fogelin that there would be no point to assembling arguments in such contexts, since argument has multiple functions, only one of which is to resolve disputes; but it is to say that the point of argument in such contexts is significantly restricted.

\section{Defending deep disagreement}

Fleshing out Fogelin's view in this way by itself provides some support for this immodestly modest claim. In addition, however, any adequate defense must respond to criticism. Andrew Lugg (1986), for example, claims that even Fogelin's modest view is far too radical:

It is one thing to maintain that individuals may find themselves in the situation of being unable to resolve their differences on the basis of shared commitments, quite another to conclude that in such cases argument is pointless .... (p. 48)

For argument to provide rational dispute resolution, Lugg thinks, we need not begin with an elaborately shared understanding, because that is something that may result from engaging in the practice of argument. 
What I am suggesting is that we take common viewpoints to be what individuals move towards rather than what they fall back to. Instead of thinking of shared beliefs as "a common court of appeal", we should think of it as a product of discussion, argument, and debate. (p. 49)

If Lugg is correct, Fogelin has described too narrowly the deployment of argument in practical conflict resolution, and so his troubling conclusion can be resisted.

There are unquestionably examples of disagreement in which engaging in "discussion, argument, and debate" leads to a new shared understanding. In fact, it appears to happen regularly in local political disputes over, for instance, whether a new football stadium should be built using taxpayers' money, whether protecting the local environment is consistent with building a new light rail line, or whether the city should entice more business into the area in order to increase its sales tax revenue. In such cases, Lugg's suggestion that interlocutors can build to a common understanding by retreating to neutral ground, untangling, coordinating and synthesizing ideas, examining assumptions, reviewing alternative proposals, and negotiating conflicting demands (p. 49) seems perfectly reasonable. But Fogelin's point is not that what goes on in such dialectical free-for-alls cannot involve argument, or even that the resulting resolution cannot sometimes be represented as accomplished through nothing but serial arguments. It is that everything rests on how much is shared to begin with. And when that is not enough to resolve the conflict through the simple giving of reasons against a stable background of understanding and competence, it will require altering this background in nonincremental ways, which is another sort of thing entirely. And we misrepresent the source of success when things do work out in such circumstances as well as the nature of our disappointment when they do not if we characterize as argument the activity required to make argument possible. And this is especially damaging to the enterprise of informal logic when it encourages us to distort the role and exaggerate the prospects of argument form in the contexts of social controversy or philosophical abstraction that tempt our attention. For these are precisely the cases in which neither side can lay claim to the level of understanding or clarity of competence that characterize those quotidian uses of argument form that establish our expectations of it.

We recognize this perhaps most easily in the second of these contexts, that is, in abstract controversy over various forms of skepticism (external world, other minds, induction), for instance, or the compatibility of free will with determinism. The exotic terms of these disputes and their interminability among uncontroversially informed and intelligent people makes it fairly clear that they lie at the outer edge of our competence and understanding. When we do schematize an argument in these disputes, it rarely captures anything like a "normal" episode in which a reason simply ends debate by appeal to a shared competence. Schematizing may help, but the work is usually done by the way in which a simple structure can organize our thinking as we work through subtle conceptual interconnections. And the rare 
epiphanies typically occur when study and reflection casts the structured sentences in a new light, providing their words with unsuspected significance. Only in this way can we begin to understand a philosopher's suggestion that metaphors don't mean what they seem to or, about free will, that "compatibilism is compatible with incompatibilism".

But if it's easy to see that philosophical arguments are so unlike "normal" ones, this is far more difficult when dispute concerns the hot social issues we like to treat in our classes, such as affirmative action, assisted suicide, universal health care, capital punishment, Roe $v$. Wade, and display of the Ten Commandments. For these may be conducted in familiar vocabulary and do not obviously fall in a special discipline of study. So it's easy to think that no special skill is required to reason about such things.

When differences on topics like these resist easy treatment, however, they do so typically because those differences, no less than exotic philosophical ones, reach deep into what goes without saying beneath the flow of talk that invests our words and sentences with the significance they have for us. Fogelin points us to Wittgenstein's On Certainty (Wittgenstein, 1969) at this point in his discussion precisely because a major theme of this work is how quickly we run up against the limits of our ability to talk and think when our conversation drifts in this direction. For our confident "going on together" in application of familiar concepts here depends on our

sharing routes of interest and feeling, senses of humor and of significance and of fulfillment, of what is outrageous, of what is similar to what else, what a rebuke, what forgiveness, of when an utterance is an assertion, when an appeal, when an explanation-all the whirl of organism Wittgenstein calls 'forms of life.' (Cavell, 1969, p. 52)

These are of course just what we do not share in deep normative controversy and, as the difficulty of Wittgenstein's text suggests, even seeing this clearly, not to mention articulating its role in our disarray, requires extraordinary insight and patience.

So the hazard these cases represent for the pedagogy of informal logic is twofold. First it requires highly refined analytical skills - not ones to be acquired by argument or at all in a single semester-just to characterize disagreements at this level, to even see where the issue lies and that it may vary substantially from person to person. Second, even if we get this far, we must be prepared to find that the differences can involve items on Cavell's list that no thoughtful person has ever considered treatable epigrammatically. A third, less formal matter may actually be the greatest hazard in practice: that the felt urgency of these issues naturally undermines the patience required to treat a subject of this depth and subtlety. The option of thinking the obduracy lies in the personal flaws of the opposition rather than the difficulty of the topic may be irresistible. ${ }^{3}$ 


\section{Beyond argument: Why deep disagreement is not quite as bad as it seems}

The word "argument" is of course used quite broadly to cover everything from independent variables in mathematics to the upleasantries antecedent to gunfire in saloon parking lots. So the point here is not a lexical one. The issue concerns the specific set of expectations attached to the word in philosophical contexts and especially in the developing conversation of Informal Logic. In this context, characterizing as argument the usual sort of articulate wrangling provoked by disagreement in even the most civilized forums suggests that distinguishable activities bearing very different relations to the outcome of that wrangling be evaluated according to a single narrow standard. But if we try to assimilate these cases to the paradigms of effective reasons-giving by representing their substance in schematized form, we will omit much, usually most of what was required to reach agreement. And it is here that the problem lies in what Fogelin and his most enthusiastic defenders may have in common with many in the Informal Logic literature who find his result appalling.

This is that the resolution of disagreement is rational only if it results from arguments. But we often change our minds about something as the result of education and experience the significance of which cannot be captured in a sentence or two. When we read books, take courses, sharpen our perceptual and diagnostic skills in application, and simply knock about in the world with our eyes and ears open, we gain understanding in vast sweeps, not one proposition at a time. We must learn an enormous amount this way before the practice of giving reasons is accessible to us at all; and the value of that practice then rests on the objectivity of the understanding thus accumulated. To stigmatize our standard ways of learning as irrational demeans the concept of rationality.

So we may reasonably endorse dispute resolution on this basis too. If the topic is one on which the contending parties can guide themselves to a common understanding in recognizably standard ways, the resulting agreement will have credentials as good as any resulting from canonical argument evaluation. But this also makes clear why we cannot in general award such credentials to the result of the dialectical free-for-all that occurs when people get together to "work out their differences" on a contentious matter. For, as anyone who's served on an unruly jury will attest, what's effective in such forums will usually embroil the above sort of "rational" activity in a complicated mix of friendly cajoling, facile eloquence, strategic positioning, social pressure, veiled threats, and pure negotiation: activities that are distinctly not standard ways of accumulating understanding about the truth of a proposition. ${ }^{4}$

Of course the earlier caveats naturally apply here too. For when we fail to share all those things Cavell finds in a "form of life" this will show up in our sense of what procedures are standard: one man's facile eloquence is another's splendidly 
instructive figure. Which explains why in general, when we try to discuss matters on which we do not share a sense of what appeals are acceptable, the problem is one of communication, resulting in cross purposes more than transparent disagreement. For these differences affect the very significance of the words expressing the judgments based on them. ${ }^{5}$ This does not, as sometimes supposed, constitute a formal barrier to understanding each other. But given the special training and patience required to even see when a standard is being adhered to rather than violated, it does gesture at the sort of challenge we face in doing so.

\section{Notes}

'We only mean to suggest that Fogelin's "modest" claim is modest with respect to the more radical claim with which he concludes the paper. Both claims are, for reasons that will become clear as we proceed, not modest at all.

${ }^{2}$ This example is based on the only example Fogelin (1985) gives us of a normal argumentative exchange.

${ }^{3}$ Fogelin (1985) cites Wittgenstein (1969) on this point, "Where two principles really do meet which cannot be reconciled with one another, then each man declares the other a fool and a heretic." $(1985$, p. 6) A good illustration of this point can be seen in the current debate over evolution and intelligent design creationism (IDC). Proponents of both views tend to insult the other side as much as engage it. Wittgenstein's diagnosis is surely correct in this case. Just as IDC proponents tend to use the design vocabulary to express a certain spiritual commitment, proponents of evolution often use Darwinian vocabulary to simply express a secular worldview.

${ }^{4}$ This point suggests a fundamental problem with the pragma-dialectical theory of argumentation. See Turner (2000) for a detailed discussion of this problem.

${ }^{3}$ This is why one might be wary of the strategy for resolving disagreements in cases such as abortion, euthanasia, and distributive justice developed by Ronald Dworkin (1994, 2000). Dworkin claims, for example, that disputants in the abortion debate really do agree on the fundamental issue-both sides accept the abstract principle that life is sacred. But as Campolo (this volume) suggests, this move to an abstract principle does little real work. The dispute arises precisely because words like 'sacred' owe their significance to radically different takes on our existence, which must be addressed before such terminology can express a common commitment. Without this, common vocabulary just makes it more likely disputants will talk past one another.

\section{References}

Cavell, S. 1969. Must We Mean What We Say? New York: Charles Scribner's Sons.

Campolo, C. 2005. "Treacherous ascents," Informal Logic, 25.1: 37-50.

Dworkin, R. 1993. Life's Dominion: An argument about abortion, euthanasia and individual freedom. New York: Alfred A. Knopf.

Dworkin, R. 2000. Sovereign Virtue. Cambridge: Harvard University Press.

Davson-Galle, P. 1992. "Arguing, Arguments, and Deep Disagreements," Informal Logic, 14.1:147-156. 
Fogelin, R. 1985. “The Logic of Deep Disagreements," Informal Logic, 7: 1-8. (Reprinted in Informal Logic, 25,1:3-11.)

Lugg, A. 1986. “Deep Disagreement and Informal Logic: No Cause for Alarm," Informal Logic, 8: 47-51.

Pennock, R. 1999. Tower of Babel: The Evidence Against the New Creationism. Cambridge, MA: The MIT Press.

Turner, D. 2000. Fallacies and the Concept of an Argument. Ph.D. Thesis. Riverside: University of California.

Wittgenstein, L. 1969. On Certainty. Oxford: Blackwell.

Wright, L. 1995. "Argument and Deliberation: A Plea for Understanding," The Journal of Philosophy, 92, 565-586.

Dale Turner

Department of Philosophy

California State Polytechnic University, Pomona Pomona, CA 91768

dturner@csupomona.edu

Larry Wright

Department of Philosophy

University of California, Riverside HMNSS Building, Room 1604

900 University Avenue

Riverside, CA 92521

larry.wright@ucr.edu 